\title{
Estresse ocupacional em profissionais de uma Unidade de Pronto- Atendimento (UPA): práticas interventivas de educação em saúde
}

\author{
Occupational stress in professionals of an Emergency Care Unit (ECU): intervention \\ practices in health education
}
Estrés laboral en profesionales de una Unidad de Atención de Emergencia (UAE): prácticas de intervención en educación en salud

Amanda Ouriques de Gouveia ${ }^{1 *}$, Elcirlen dos Santos da Cruz $^{2}$, Leudilane Reis da Silva ${ }^{2}$, Bruna Luiza de Souza Costa ${ }^{2}$, Aline de Jesus Alcântara da Silva², Daniele Reis Mendes², Jaciara da Silva Barroso Martins ${ }^{2}$, Aline Carvalho da Silva ${ }^{2}$, Camila Patricia Pereira Sousa ${ }^{2}$, Aline Ouriques de Gouveia ${ }^{3}$.

\section{RESUMO}

Objetivo: O objetivo do presente estudo é relatar a experiência dos acadêmicos, perante a aplicação de práticas de Educação em Saúde em profissionais atuantes em uma Unidade de Pronto Atendimento, sobre os riscos do estresse profissional, desenvolvimento da Síndrome de Burnout e prevenções para tal. Relato de experiência: Trata-se de um estudo do tipo relato de experiência, feito por discentes de um curso de graduação em enfermagem. Para a realização da ação interventiva, fora utilizada a metodologia da problematização, em consonância com o arco de maguerez. O planejamento e execução da ação foram divididos em cinco etapas, sendo elas: observação da realidade, identificação de pontos-chave, teorização, hipóteses de solução e aplicação à realidade. Na aplicação, a ação deu-se em três momentos: a realização da palestra informativa sobre o estresse ocupacional; a execução de uma prática lúdica com os profissionais locais; e finalizando com uma canção em homenagem aos servidores e em valorização à vida. Considerações finais: As práticas aqui relatadas demonstraram retorno ao atingir e conscientizar os profissionais, estes os quais, relataram identificação com os sintomas expostos, além de correlacionarem os motivos ocupacionais que levem a tal. De tal forma, as práticas tiveram êxito em seus resultados.

Palavras-chave: Educação em saúde, Assistência ambulatorial, Estresse ocupacional.

\section{ABSTRACT}

Objective: The objective of this study is to report the experience of academics, regarding the application of Health Education practices in professionals working in an Emergency Care Unit, about the risks of professional stress, the development of Burnout Syndrome and preventions for this. Experience report: This is an experience report type study, carried out by undergraduate nursing students. To carry out the interventional action, the problematization methodology had been used, in line with the maguerez arch. The planning and execution of the action were divided into five stages, which are: observation of reality, identification of key points, theorization, hypotheses of solution and application to reality. In the application, the action took place in three moments: the holding of an informative lecture on occupational stress; the execution of a playful practice with the local professionals; and ending with a song in honor of the servants and in appreciation of life. Final considerations: The practices reported here showed a return when reaching and raising awareness among professionals, who reported identifying themselves with the exposed symptoms, in addition to correlating the occupational reasons that lead to such. In such a way, the practices were successful in their results.

Key words: Health education, Ambulatory care, Occupational stress.

1Fundação Santa Casa de Misericórdia do Pará, Belém - PA. *E-mail: enf.amandaouriques@hotmail.com

${ }^{2}$ Faculdade de Teologia, Filosofia e Ciências Humanas Gamaliel (FATEFIG), Tucuruí - PA.

3Universidade do Estado do Pará (UEPA), Tucuruí - PA.

SUBMETIDO EM: 7/2020 | ACEITO EM: 8/2020 ｜ PUBLICADO EM: 10/2020




\section{RESUMEN}

Objetivo: El objetivo de este estudio es reportar la experiencia de los académicos, en cuanto a la aplicación de prácticas de Educación para la Salud en los profesionales que laboran en una Unidad de Atención de Emergencias, sobre los riesgos del estrés profesional, el desarrollo del Síndrome de Burnout y su prevención. Informe de experiencia: Se trata de un estudio tipo informe de experiencia, realizado por estudiantes de licenciatura en enfermería. Para llevar a cabo la acción intervencionista se había utilizado la metodología de problematización, en línea con el arco de maguerez. La planificación y ejecución de la acción se dividió en cinco etapas, que son: observación de la realidad, identificación de puntos clave, teorización, hipótesis de solución y aplicación a la realidad. En la aplicación, la acción se desarrolló en tres momentos: la realización de una charla informativa sobre estrés laboral; la realización de una práctica lúdica con los profesionales locales; y terminando con una canción en honor a los sirvientes y en agradecimiento a la vida. Consideraciones finales: Las prácticas aquí reportadas mostraron un retorno a la hora de llegar y sensibilizar a los profesionales, quienes informaron identificarse con los síntomas expuestos, además de correlacionar los motivos ocupacionales que los llevan. De tal manera, las prácticas tuvieron éxito en sus resultados.

Palabras clave: Educación en salud, Atención ambulatoria, Estrés laboral.

\section{INTRODUÇÃO}

De acordo com Marques SV, et al. (2011) a ocupação serviçal é uma constituição sócio-histórica, baseada em um processo instável e constantemente mutável. O estudo antes referenciado, institui o conceito do trabalho como dinâmico, onde, este, varia de uma sociedade para outra e de tempos em tempos, podendo somente ser compreendido no contexto em que está sendo analisado.

Para Meira LC, et al. (2015), no contexto atual, o universo do trabalho/ocupação, têm presenciado mudanças consideravelmente intensas. Problemas financeiros e transtornos psicológicos são comuns na atualidade e principalmente no contexto ocupacional. O desemprego toma proporções vigentes e de maneira injusta os proletariados são subjugados às atividades laborais com altas cargas horárias, em ambientes insalubres e extenuantes.

No âmbito da saúde, Almeida LGN, et al. (2012) afirma que devido às particularidades das atividades desenvolvidas, os servidores estão exponencialmente mais expostos aos riscos físicos, químicos, biológicos e psicossociais. Tais exposições contínuas e heterogêneas, podem promover distúrbios nos trabalhadores e gerar detrimentos às instituições de saúde, vindo a interferir na qualidade da assistência prestada aos pacientes, tendo em vista que o saldo de saúde do servidor vem a interferir diretamente no desenvolvimento das suas atividades laborais.

Os Transtornos Mentais Comuns (TMC) e a consequente Síndrome de Burnout (SB) ou Síndrome do Esgotamento Profissional são distúrbios decorrentes do estresse ocupacional, este, podendo vir a acometer diversos tipos de profissionais. Tais distúrbios dar-se-á a partir dos principais fatores desencadeantes: 0 excesso de trabalho atrelado à pressão e às responsabilidades contínuas.

Os trabalhadores acometidos por tais apresentam como sintomas: insônia, fadiga, irritabilidade, que na $\mathrm{SB}$, evoluem para o cansaço excessivo e estresse prolongado, desgastes, estes, que prejudicam os aspectos físicos e emocionais do indivíduo, podendo alcançar o esgotamento profissional (KESTENBERG KV, 2018).

No que tange ao conhecimento profissional frente aos riscos ocupacionais, De Oliveira CS, et al. (2015) afirma que a conexão entre educação e saúde se dá como uma das mais extensas fontes de fazer saúde. De tal modo, todos podem ser receptores deste conhecimento, mesmo os profissionais. O Ministério da Saúde conceitua Educação em Saúde como: "Processo educativo de construção de conhecimentos em saúde que visa à apropriação temática pelo público alvo [...] (BRASIL, 2020).

De tal forma, o objetivo do presente estudo é relatar e descrever as experiências de acadêmicos do curso de Enfermagem, perante a aplicabilidade de práticas de Educação em Saúde para com profissionais atuantes em uma Unidade de Pronto Atendimento, sobre os riscos do estresse profissional, desenvolvimento da Síndrome de Burnout e prevenções para tal. 


\section{RELATO DE EXPERIÊNCIA}

O presente estudo consiste em um relato da experiência de acadêmicos do curso de graduação em enfermagem, de uma faculdade do interior do estado do Pará, na cidade de Tucuruí. O trabalho surgiu a partir de estímulo, por parte da docente responsável pelo componente curricular: Enfermagem em Saúde Mental, frente à necessidade de práticas de educação em saúde para com profissionais, sobre distúrbios psicossociais de causas ocupacionais.

A partir do estímulo, os acadêmicos escolheram a metodologia a ser seguida para a realização da prática. Metodologia, esta, sendo a da problematização em consonância com o uso do arco de maguerez e suas cinco etapas subjacentes: observação da realidade, identificação de pontos-chave, teorização, hipóteses de solução e aplicação a realidade. Para a realização da intervenção por meio da educação em saúde para com os profissionais, os discentes foram orientados a preparar materiais relacionados ao tema: "Estresse ocupacional e suas consequências".

A experiência fora realizada em 5 etapas, como proposto pela metodologia supracitada. No seu primeiro momento, fora realizada a observação da realidade, onde, previamente à ação interventiva, os acadêmicos, fizeram uma visita técnica ao local de estudo, este sendo a única Unidade de Pronto Socorro (UPA) da cidade, para a observação comportamental dos profissionais ali atuantes. Durante o período de observação e a partir de conversas com profissionais, fora constatada uma sobrecarga de trabalho, relacionando-os também, à poucas condições de trabalho e ambiente superlotado de pacientes.

Após a visualização da realidade antes citada, foram identificados pontos-chave estes os quais, se destacaram: sobrecarga de trabalho, ambiente insalubre com riscos biológicos e psicossociais aos profissionais e alta demanda de público em paralelo ao baixo número de profissionais para o atendimento e acolhimento. Por conseguinte a tal, os acadêmicos seguiram para a teorização, onde está, deu-se por pesquisas em bancos de dados científicos, sendo eles: CAPES Periódicos, Sistema de Informação Científica Redalyc e o Scientific Eletronic Library Online (SCIELO), com os seguintes descritores: Educação em Saúde, Estresse Ocupacional, Burnout e Urgência e Emergencia.

Em seguida à pesquisa bibliográfica, constatou-se a necessidade do diálogo por meio da educação em saúde, adjunto aos profissionais da saúde, para que assim, estes, tomem consciência de seus limites e saibam reconhecer o linear entre a força motriz de trabalho e a exaustão decorrente das atividades laborais

$\mathrm{Na}$ aplicação à realidade escolhida, partir da condensação dos resultados encontrados na literatura e das hipóteses de soluções sugeridas por estudos de mesmo escopo, fora moldado o planejamento da ação, sendo ela constituída em três fases:

1) a produção do material físico, sendo estes no modelo de pôsteres informativos, os quais posteriormente, poderiam ficar nas paredes do espaço físico local;

2) seguido da eventual prática de Educação em Saúde, para com os profissionais atuantes na relatada Unidade de Pronto-atendimento, do conteúdo presente nos materiais, sobre os riscos, sintomas, consequências do estresse, desenvolvimento da Síndrome de Burnout e prevenção, para os profissionais;

3) finalizando com uma curta representação lúdica, ressaltando questões como o desgaste e a desvalorização profissional, conseguinte a uma homenagem aos profissionais da saúde, com uma música em ode à valorização a vida e a saúde mental individual.

A intervenção fora realizada três vezes em horários e turnos distintos, para que todos os profissionais ali atuantes pudessem ser receptores do conteúdo repassado pelos acadêmicos. A recepção dos profissionais enfermeiros, médicos e corpo técnico fora extremamente positiva, onde pôde-se constatar que vários deles apresentavam os sintomas da síndrome do esgotamento profissional, mesmo desconhecendo tal, segundo relato dos mesmos. Os principais sintomas relatados por estes foram: insônia, fadiga, irritabilidade e dificuldade de concentração. Também houvera dúvidas sobre o assunto explanado e relatos dos professionais sobre seus desafios do dia-a-dia. Além de uma conjunta comoção por parte da equipe, após o momento musical em ode à valorização da vida. 
A equipe, evidenciou como principais estressores a alta demanda de trabalho e as péssimas condições de realização deste, por via de infraestrutura insalubre e poucos materiais de trabalho necessários. Também fora exposta a constante agressão verbal e eventualmente, física, sofrida pelos profissionais, por parte dos pacientes que entram requisitando atendimento imediato e se deparam com longas filas de espera. Esses são alguns dos principais fatores estressantes que corroboram para o estabelecimento de sintomas da síndrome do estresse ocupacional, fatores estes, intrínsecos a realidade da área da saúde no Brasil.

As práticas de educação em saúde antes relatadas, tiveram como objetivo a gerar a autopercepção do risco causado pelo trabalho extenuante, nos profissionais, visando a emancipação destes, frente ao reconhecimento dos sinais e sintomas, para que possam ser tratados ou prevenidos. Além de que, um profissional que está com sua saúde em dia, é muito mais apto para o fornecimento de saúde de qualidade ao cliente, resultando assim em um retorno positivo, tanto aos profissionais, quanto à população.

\section{DISCUSSÃO}

A utilização da metodologia ativa da problematização em consonância com o arco de maguerez, como utilizada na prática de educação em saúde aqui relatada, segundo Silva HRS, et al. (2020), faz-se de grande eficácia no âmbito da prevenção, combate e solução de adversidades encontradas em instituições de saúde. Tais métodos, segundo os autores antes referidos, para os envolvidos, têm grande potencial no despertar de interesse, ao passo em que os discente se envolvem diretamente com a teorização e prática, por poderem participar ativamente na construção e planejamento da ação, valorizando assim, o engajamento, percepção de poderio e pertencimento. Assim, demonstrando a eficácia na utilização de tais meios de ensino e intervenção.

Fujita JALM, et al. (2016), em seu estudo bibliográfico, assegura que a aprendizagem torna-se ainda mais eficaz no momento em que o conteúdo explanado em sala de aula, se faz presente no cotidiano dos acadêmicos a partir da metodologia da problematização, sendo esta, a qual o docente assume o papel de guia ao conduzir os alunos à realidade apresentada, deixando-os realizar a prática de ensino, subvertendo a maneira tradicional de ensino onde os discentes surgem apenas como receptores, passando dessa forma, a serem propagadores de ensino.

Berbel NAN e Gamboa SAS (2011), afirmam que a utilização dos cinco passos do arco de maguerez (observação da realidade, identificação de pontos-chave, teorização, hipóteses de solução e aplicação a realidade) em adjunto a metodologia da problematização, acarretam uma das formas mais eficazes de intervenção à realidade.

O processo de educação em saúde, nos moldes dos quais foram realizados no presente relato, segundo Falkenberg MB, et al. (2014) dar-se-á como um processo político-pedagógico, este o qual leva ao desenvolvimento de um pensar crítico e reflexivo, permitindo o receptor a desvelar a realidade a qual fora explanada e, de tal forma, propor ações transformadoras que levem o indivíduo à sua autonomia e emancipação. De tal maneira, estabelecendo assim, autopercepção aos indivíduos receptores da estratégia, como no caso atual, onde os profissionais puderam perceber em si os sinais físicos e psicológicos do estresse ocupacional, levando-os a uma melhor expectativa de autocuidado.

Além da maneira tradicional de intervenção, utilizada por parte dos discentes, para com os profissionais, por meio de palestras informativas, também fora utilizada a ludicidade, a qual Coscrato G, et al., (2010) assegura que, esta, figura-se como método alternativo, o qual contempla os critérios de um processo de ensino-aprendizagem efetivo, onde chama-se a atenção do receptor, promovendo reciprocidade, e levando a discussões entre todos os presentes.

Campos CNA, et al. (2012), demonstraram através de seu estudo, que a educação em saúde, encontrou nas artes cênicas, um meio para aprimorar as relações interpessoais de preceptor/receptor, onde tal, permitirá uma visão integral dos indivíduos, fomentando uma visão contextualizada e mais real do assunto que virá a ser discutido. O teatro, foi uma das ferramentas utilizadas pelos discentes do presente relato, para com os profissionais de saúde, onde pôde-se perceber que na literatura, tal meio dá-se como efetivo. 
Para além das vias metodológicas do relato, o tema acerca do estudo e intervenção, os distúrbios psicológicos decorrentes de práticas laborais, são bastante presentes na literatura, quando se trata de profissionais da saúde. No estudo de Rodrigues EP, et al. (2014), realizado com enfermeiros de um hospital, sobre a prevalência de transtornos mentais comuns, constatou-se o alarmante número positivo em $35 \%$ dos participantes, evidenciados também através de relatos acerca de alta demanda psicológica e baixo controle de atividades laborais, apontando que as condições de trabalho não são adequadas para a realização de um trabalho efetivo. Tais relatos condizem com a realidade exposta pelos profissionais receptores da ação aqui relatada.

Braga LC, et al. (2010), relata em seu estudo que os principais sintomas presentes na síndrome do estresse profissional, tema estabelecido para a realização da ação de educação em saúde aqui relatada, estão os descritos como espectro Transtornos Mentais Comuns (TMC), onde estão presentes a insônia, esquecimento, dificuldade de concentração, irritabilidade, fadiga e etc. O que demonstra correlação direta com o que fora relatado com os profissionais durante a abordagem interventiva no presente estudo.

Em estudo bibliográfico realizado por Da Silva JF, et al. (2020), pode afirmar que, no âmbito da saúde, os profissionais mais acometidos por tal síndrome, foram os enfermeiros. Vasconcelos EM e De Martino MMF (2017), relataram que enfermeiros de Unidades de Pronto Atendimento (UPA) são os que mais sofrem, continuamente, influências de diversos estressores encontrados no ambiente de trabalho.

Devido a ocupação laboral ser relativamente exaustiva, tais profissionais estão predispostos a virem desenvolver o estresse ocupacional, que futuramente pode vir, de tal forma, desencadear a Síndrome de Burnout, tal qual, esta, desconhecida por um grande número de profissionais.

Oliveira SN, et al. (2015), afirma quem as UPAs foram criadas para desafogar os pronto-atendimentos hospitalares, estabelecendo-se na atenção de média complexidade, figurando como peça importante da rede de saúde. França FM, et al. (2012), aponta que a atuação, principalmente, da enfermagem, em serviços de pronto-socorro, é a mais afetada pelo estresse ocupacional. A partir disso deu-se continuidade a quarta fase do processo.

Moreno FN, et al. (2011), descreveu como principais formas de intervenção e prevenção frente ao estresse profissional os seguintes meios: meditação, atividade física, educação em saúde, estabelecimento de melhorias na relação indivíduo-grupo, onde ocorrerá melhorias na comunicação e convivência grupal, mudanças nas condições físicas do local e entre outras. Evidenciando-se assim a eficácia do método interventivo escolhido para a ação com o público alvo do estudo.

Concluiu-se, então, que as práticas de educação em saúde para com profissionais, se fazem necessárias, levando em consideração os diversos estressores e fatores que evidenciam uma prática de trabalho não saudável dentro da área da saúde. Temas como a saúde mental devem ser tratados a exaustão, para que os profissionais se façam cientes de tais sintomas e saibam reconhecer, antes de virem a desenvolver doenças como a Síndrome de Burnout. De tal maneira, os preceptores das práticas interventivas propiciarão um meio de promover a saúde como, também, corroborarão com o institucionamento de um melhor serviço de saúde prestado pelos profissionais, tornando-se extremamente eficaz no âmbito da saúde coletiva.

\section{REFERÊNCIAS}

1. ALMEIDA LGN, et al. Riscos ocupacionais na atividade dos profissionais de saúde da atenção básica. Revista Enfermagem Contemporânea, 2012. 1(1): 142-154.

2. BERBEL NAN, GAMBOA SAS. A metodologia da problematização com o Arco de Maguerez: uma perspectiva teórica e epistemológica. Filosofia e Educação, 2011. 3(2): 264-286

3. BRAGA LC, et al. Condições de trabalho e transtornos mentais comuns em trabalhadores da rede básica de saúde de Botucatu (SP). Ciência \& Saúde Coletiva, 2010; 15(1): 1585-1596.

4. BRASIL, MS. Secretaria de Gestão do Trabalho e da Educação na Saúde. Departamento de Gestão e da Regulação do Trabalho em Saúde. Câmara de Regulação do Trabalho em Saúde, 2020.

5. CAMPOS, CNA et al. Reinventando práticas de enfermagem na educação em saúde: teatro com idosos. Escola Anna Nery Revista de Enfermagem, 2012; 16(3): 588-596.

6. CERVERA DPP, et al. Educação em saúde: percepção dos enfermeiros da atenção básica em Uberaba (MG). Ciênc. saúde coletiva, 2011. 16(1): 1547-1554. 
7. COSCRATO G, et al. Utilização de atividades lúdicas na educação em saúde: uma revisão integrativa da literatura. Acta paul. Enferm, 2010; 23(2): 257-263.

8. DA SILVA JF, et al. Síndrome de Burnout em profissionais de Enfermagem no contexto da Atenção Básica. REAS, 2020. 2320(39): 1-7.

9. DE OLIVEIRA CS, et al. Educação em saúde: uma estratégia para a promoção do aleitamento materno. Revista Educação em Saúde, 2015. 3(2): 20-19

10. FALKENBERG MB, et al. Educação em saúde e educação na saúde: conceitos e implicações para a saúde coletiva. Ciênc. saúde coletiva, 2014. 19(3): 847-852.

11. FERRARI R, et al. Avaliação da síndrome de burnout em profissionais de saúde. Revista Eletrônica Gestão e Saúde, 2012. 1(3): 868-883.

12. FRANÇA FM, et al. Burnout e os aspectos laborais na equipe de enfermagem de dois hospitais de médio porte. Revista Latino-Americana de Enfermagem, 2012. 20(5): 961-970.

13. FUJITA JALM, et al. Uso da metodologia da problematização com o Arco de Maguerez no ensino sobre brinquedo terapêutico. Revista Portuguesa de Educação, 2016. 29(1): 229-258.

14. KESTENBERG KV. Síndrome de Burnout: O que é, os sintomas e o tratamento. Psicologia viva. [S.I]: 06 Julho 2018. Disponível em: https://blog.psicologiaviva.com.br/sindrome-de-burnout/. Acesso em: 09 jun. 2020.

15. MARQUES SV, et al. Saúde, trabalho e subjetividade: absenteísmo-doença de trabalhadores em uma universidade pública. Cad. EBAPE, 2011. 9(1): 668-680.

16. MEIRA LC, et al. Síndrome de Burnout: suscetibilidade em enfermeiros atuantes na urgência e emergência de um hospital público de Campina Grande, PB. Rev. G\&S, 2015. 6(2): 1289-1320.

17. MORENO FN, et al. Estratégias e intervenções no enfrentamento da síndrome de burnout. Rev enferm UERJ, 2011; 19(1): 140-5.

18. OLIVEIRA SN, et al. Unidade de Pronto Atendimento - UPA 24h: percepção da enfermagem. Texto \& Contexto Enfermagem, 2015. 24(1): 238-344.

19. VASCONCELOS EM, DE MARTINO MMF. Preditores da síndrome de burnout em enfermeiros de unidade de terapia intensiva. Rev Gaúcha Enferm, 2017. 38(4): e65354.

20. SILVA HRS, et al. Práticas de educação em saúde desenvolvidas pelo núcleo de ensino e pesquisa (NEP) de um hospital do interior do estado do Pará. REAS, 2020; 12(8): e3640. 